\title{
As políticas educacionais hegemônicas na industrialização tardia do Paraná: a proposta de Erasmo Pilloto, matrizes, alcances e contradições
}

\author{
Adálcia Canedo da Silva Nogueira \\ Professora Titular da FAFICOP, Cornélio Procópio/PR \\ Mestranda em Educação pela UEL
}

\section{Resumo}

As políticas educacionais materializam as ideias dominantes de uma determinada época e tempo histórico, no campo da Educação. A tradição educacional e pedagógica denominada Educação ou Escola Nova, em sua implementação ou ordenamento identitário próprio, tal como se constituiu na realidade do Brasil, emergente a partir dos anos 1930, quando se estrutura um novo modelo de economia e sociedade no país, constituído a partir da superação das relações pré-capitalistas e da construção da hegemonia das relações orgânicas de natureza capitalista, urbano-industriais, não foi uma realidade linear e concomitante no país. O estado do Paraná, uma unidade institucional periférica do processo de industrialização tardia do Brasil apresenta movimentos de ideias e de ordenamentos das políticas educacionais no Estado com características tensionadas entre a manutenção das teses e conceitos, disposições e concepções tradicionais, de natureza elitista e contornos idealistas, aristocráticos e religiosos, e as novas inspirações de natureza liberal e humanista, próprio do corolário escolanovista. As políticas de Erasmo Pilloto, o secretário estadual de educação do Paraná entre 19XX e 19XX é uma figura política e pedagógica central para o decifrar das contradições do ideário liberal da escola nova no Paraná e o objeto nuclear do presente estudo. Analisa a implantação da escola normal e da escola normal regional no Paraná. Estuda as diretrizes estaduais para a viabilização de um projeto de formação de professoras primárias para as escolas rurais, a Escola Normal Regional. As propostas foram diferenciadas e existiram em períodos distintos, contudo sofreram sempre a influência dos fatores sociais, econômicos e políticos ao qual estiveram ligados. A filosofia proposta era a formação do homem, principalmente das camadas socialmente excluídas. No Paraná a Escola Normal Regional esteve atrelada à função social de alfabetizar e estabelecer o homem no campo, em um contexto do desenvolvimento sócio econômico contraditório, enquanto no cenário nacional se afirmava a urbanização e a indústria no Paraná se assistia ao esgotamento da economia ervateira e auge da cultura do café.

Palavras-chave: Educação; Escola Nova; Escola Normal; Escola Normal Regional. 


\begin{abstract}
Educational policies materialized the ideas of a particular age and dominant historical time, in the consideration about education. The pedagogical and educational tradition called New School or New Education, in their own implementation or regional identity, as constituted in the reality of Brazil, emerging from the years 1930, when designing a new model of economy and society in the country, constituted from the overrun previous capitalist relations and construction of hegemony of capitalist nature organic relations, urban-industrial, was not a linear reality and concomitant in the country. The State of Paraná, one institutional unit peripheral late industrialization process of Brazil presents ideas and movements of orderings of educational policies in the State with tensioned characteristics between the maintenance of theses and traditional conceptions, concepts and provisions, of nature and elitist, aristocratic and religious contours idealists, and the new inspirations of humanist and liberal nature, own the corollary "escolanovista". Erasmo Pilotto, the State Secretary of education of Paraná between 1930 and 19 is a pedagogical and political figure central to the decipherment of the contradictions of "escolanovista" ideal in Paraná and the nuclear object of this study. Analyzes the deployment of the normal school and normal school regional in Paraná. Studies the State guidelines for enabling a primary teachers training project for rural schools, the Regional Normal School. The proposals have been differentiated and existed in different periods, but always suffered the influence of social, economic and political factors which were connected. The philosophy was the formation of man proposal, especially socially excluded layers. In Parana Regional Normal School was tied to the social function of teaching and to establish the man in the field, in a context of economic and social development, while on the national scene adversarial stated urbanization and industry in Paraná if watching the impoverishment of economy of tea production and height of the coffee culture.
\end{abstract}

Keywords: Education; New School; Normal School; Regional Normal School. 


\section{Introdução}

nísio Teixeira é o nome que todo estudante pesquisador que se
dedica a reconstruir as identidades da escola nova no Brasil
imediatamente se recorda quando aborda a tradição pedagógica denominada Escola Nova no Brasil. O baiano Anísio Teixeira tornou-se a referência nacional sobre a tradição pedagógica de cunho liberal denominada pelo neologismo escolanovismo. Mas, no Paraná, o primeiro estado sulista do Brasil, dependente do último estado do sudeste brasileiro, o nome representativo do escolanovismo é Erasmo Emiliano Pilotto. Apesar dessa inusitada comparação nominal, nosso escopo é estrutural e político. Esse autor, ainda pouco conhecido, encarnou as bandeiras e assumiu os pressupostos do movimento escolanovista no Paraná, com originais adições, em meados do século XX. É o que buscaremos destacar no presente trabalho histórico e filosófico sobre Educação.

O presente estudo remonta às origens das políticas educacionais no Estado do Paraná de natureza liberal. O artigo intenta produzir uma breve incursão no histórico da Escola Normal e do modelo de formação denominado Escola Normal Regional entre as décadas de 1930 e 1940, a partir das referências já vigentes na História da Educação brasileira consubstanciado da economia do Estado nacional. Apresentamos esse estudo com a finalidade de analisar a organização da escola normal e da escola normal regional no Estado do Paraná a partir do contexto histórico econômico e social. Entendemos ser interessante e necessário empreender uma reflexão sobre a escola normal no Paraná, mais especificamente a escola normal regional, na direção de compreender o descompasso entre os processos de industrialização e de formação contingencial de professores para as escolas rurais do interior do Estado.

$\mathrm{O}$ presente estudo foi estruturado em três momentos. $\mathrm{O}$ primeiro momento, tal como dispõe a referência metodológica que nos fundamenta, estrutura-se na busca de uma síntese histórica da economia paranaense. No segundo momento abordamos a história das ideias pedagógicas na educação 
escolar no Paraná com o devido recorte das motivações institucionais de criação do Curso Normal, especificamente da modalidade Normal Regional e suas derivações. Por último, à luz do referencial teórico e epistemológico assumido e, a partir da revisão bibliográfica necessária, consideramos a importância da produção de Erasmo Piloto e da sua original disposição de constituir a proposta da Escola Normal Regional para as escolas rurais, destacadamente para Norte Pioneiro do Paraná, região circunstancialmente propícia à recepção das políticas educacionais escolanovistas.

\section{A formação econômica e social do norte do Paraná e a expansão da educação: marcos históricos, determinações legais, registros e referências}

Na década de 1930 a economia paranaense se sustentava principalmente por atividades extrativistas que tinham limitado valor, decorrendo daí a patente deficiência na infraestrutura do Estado, como a precariedade da rede viária e o escoamento da produção pelos portos de Antonina e Paranaguá, bastante restritos em relação à economia de São Paulo, que na mesma época era alavancava pela produção do café.

O café e o mate economicamente resultavam em diferenças abissais no seu processamento, embora ambos fossem produtos de exportação nacionais. O Café em São Paulo era produzido dentro de padrões capitalistas que determinava uma demanda de produção e lucro, enquanto o mate era uma atividade extrativista precária e artesanal, com um nível de eficiência produtiva bastante modesta.

De outro lado os trabalhadores da produção do café tinham sua força de trabalho remunerada durante todo o ano, tendo poder de consumo, enquanto o trabalhador na produção extrativista ervateira contava com trabalho remunerado por seis (6) meses ao ano permanecendo o outro período em estado de penúria, sem poder aquisitivo para suprir as suas necessidades básicas, para citar alguns fatores. 
O Paraná, portanto era uma economia tardia no contexto econômico brasileiro, principalmente em relação a São Paulo. Fatores como a conjuntura nacional política e econômica após a crise de 1929, a cultura cafeeira paulista próxima aos limites do Estado, o processo de industrialização de São Paulo a partir na década de 1930 e a qualidade das terras do norte do Paraná levariam a efetiva colonização do sertão do norte Pioneiro.

Além da fertilidade da terra, havia a possibilidade de se estabelecer caminhos fluviais para o escoamento da produção do café, o que atraiu primeiramente trabalhadores mineiros, dando origem ao núcleo urbano conhecido como Colônia Mineira ou Siqueira Campos. Outros núcleos se desenvolveriam como Tomazina, Santo Antonio da Platina, Wenceslau Braz e Jacarezinho, todos no Norte Pioneiro, um passo além do Rio Paranapanema e Itararé, que marcava a divisa Paraná-São Paulo. O café atravessa os rios!

Nas décadas de 1920 e 1930 se estabelecem outros importantes núcleos Cambará, Bandeirantes, Cornélio Procópio e Andirá. Com o esgotamento de áreas produtivas do café paulista e o aumento nos preços do café no mercado internacional investidores paulistas transferem o plantio do café para uma grande área de terras entre Ourinhos e Cambará, e a produção dessas terras era exportada pelo Porto de Santos, o que demandou a construção de rodovia que ligasse o norte paranaense a São Paulo e concomitantemente determinou a expansão da ferrovia, que já chegava a Ourinhos e que, por questões estruturais econômicas, estava planejada que chegaria ao norte do Paraná e seguiria atravessando o estado até Guairá, às Margens do Rio Paraná. Uma empreitada ousada!

A construção da ferrovia teve inicio em 1920 e foi um projeto de expansão capitalista de São Paulo, intencionado absorver a produção de café iniciada no Norte do Paraná e ampliar assim a posterior produção agrícola da região. Precipuamente o projeto visava que a ferrovia cumprisse o percurso de Guairá até Assunção, capital do Paraguai. Um projeto oneroso e 
que carecia de altos investimentos que possibilitassem atravessar os sertões, além do que havia a necessidade de concessão do Governo Federal. Concessão obtida, o primeiro trecho construído da ferrovia, ligando Ourinhos a Cambará, atendia a interesses privados e, por conseguinte, por falta de capital, a construção permaneceu estacionada por anos em Cambará, numa importante fazenda do líder do grupo econômico investidor.

Segundo Bondarick (2006) essa ferrovia seria comprada e construída por ingleses como um ramal da ferrovia conhecida como Sorocabana que ligava Santos a São Paulo passando por Ourinhos. Novos produtores e potenciais proprietários foram atraídos para a região, assim como trabalhadores braçais, principalmente oriundos do Estado de Minas Gerais e do Nordeste que, desprovidos de poder de compra e de crédito, vinham em busca de lograr vender sua força de trabalho neste rincão agrícola brasileiro.

A área foi financiada por bancos estrangeiros, principalmente ingleses, e a propriedade da terra se deu por colonos paulistas, mineiros e imigrantes que beneficiados pelo "Convênio de Taubaté"” estimavam lucros provenientes do café. Esse Convênio limitava o plantio de novos cafezais nos Estados de São Paulo, Minas Gerais e Rio de Janeiro, deixando livre para o plantio de novas lavouras, regiões ainda não desbravadas como o Norte do Paraná, tal como aponta o historiador Bondarick (2006).

Até aqui a economia do norte paranaense se caracterizava pela produção artesanal e os produtos para a venda eram predominantemente rebanhos suínos criados em sistema de safra, soltos em meio ao plantio de fumo, que o porco não comia, de modo a garantir a possível concomitância produtiva. Vamos ter registros de produção para o mercado externo a partir da construção da ferrovia, na década de 1930.

As cidades nascentes se caracterizavam por serem núcleos de prestação de serviços e comércio, sempre voltados para plantio de algodão,

\footnotetext{
${ }^{1}$ Firmado em 26 de fevereiro de 1906, definiu as bases do que se chamaria política de valorização do café, e oficializou a intervenção estatal para proteger o comércio e a elevação dos preços do produto.
} 
fumo, arroz, feijão e milho, inclusive com difícil escoamento comercial com a venda a crédito (pagar na colheita ou na safra) dada a péssima qualidade das picadas e estradas. Assim “a falta de meios para vender a produção fazia com que a produção local fosse muito pobre” (STECA \& FLORES, 2008p. 126).

Os padrões sociais seguiam os padrões paulistas de aliar latifúndio e trabalho semiescravo. A criação de suínos se dá no Norte Velho, entre Ribeirão Claro e São José da Boa Vista, Siqueira Campos, Ribeirão Claro, Jacarezinho, Santo Antonio da Platina, Jundiaí do Sul, conforme afirmam STECA \& FLORES (2008) atingindo a região da Serra da Esperança Congonhinhas - Ribeirão do Pinhal - Nova Fátima - Abatiá - indo até o Rio Itararé (BONDARICK, 2006). Tivemos ainda no movimento ocupacional deste espaço geográfico a extração de madeira (a peroba, principalmente). Os safristas foram extraordinários desbravadores da região para a agricultura do café e, com a decadência econômica da safra, tornaram-se os pioneiros produtores da economia cafeeira, mudança que passa a caracterizar o processo ocupacional das terras do norte - paranaense com a adesão de muitos safristas (BONDARICK, 2006).

A formação da economia do norte pioneiro paranaense teve como fator fundamental, por tanto a cultura tardia do café, ou como postulam STECA \& FLORES (2088):

A questão da fronteira entre São Paulo e Paraná sempre ocorrei em razão da dominação inicial da primeira sobre a segunda Província. Se geograficamente foi fácil delimitar suas divisas, economicamente não foi. (STECCA \& FLORES, 2008)

Nessa matriz de produção das condições de vida material, centrada na exploração da terra e de suas riquezas, combinadas entre si de maneira inorgânica e desarticulada, não há espaço para o reconhecimento da educação como prioridade.

Nossa premissa é de que não é possível entender a educação ou a escola fora dos liames da economia e sociedade, em seus movimentos estruturais. Essas coordenadas, de natureza histórica, explicarão as marcas 
culturais e institucionais da gênese, desenvolvimento e identidade da oferta de educação e da filosofia política de inspiração da Escola Normal Regional no Norte do Paraná, quase que como uma missão emergencial, anacrônica e retardada, se tomarmos as bases de compreensão da proposta burguesa ou moderna de relação entre ensino e produção industrial e urbana.

\section{Marcos referenciais e apontamentos teóricos: O Curso Normal e o Curso Normal Regional no Paraná}

A proposta tardia de uma política educacional de natureza burguesa e moderna explica, em parte, nossa reduzida oferta de escolaridade e a precariedade sistêmica no trato das exigências educacionais. Buscaremos efetuar uma pertinente reflexão sobre o percurso histórico das políticas educacionais no Estado do Paraná, a partir do período em questão, buscando desvelar as relações estabelecidas histórica e politicamente, à luz do esclarecimento das políticas públicas hegemônicas produzidas para definir a formação de profissionais para o ensino primário no Brasil.

A carência de professores era conhecida como causa histórica. Remonta a 1867, quando o presidente da Província do Paraná, Polidoro César Burlamaque, no tocante à oferta de escola normal no estado se posicionou de maneira que reconhecia o fato, de que a formação dos professores deveria ser institucional, sob certas regras e regularidades, que outorgassem aos professores uma chancela profissional. Porém, conforme o presidente, tais instituições tornavam-se prosperas nos países civilizados:

\footnotetext{
Mas no Brasil, Srs., sinto dizê-lo, elas têm sido plantas exóticas: nascem e morrem quase no mesmo dia. Porque será isto? A razão é muito simples. O professor, entre nós, não está, nem estará tão cedo elevado à altura de uma carreira, que estimule as ambições legítimas de quem quer que seja, e muito menos abra a porta a aspirantes distintos. Por via de regra só quer ser professor, quem não pode ser outra coisa (PROVÍNCIA do Paraná. Relatório de 1867, p. 30 a 32 apud CASTANHA, 2008.p.23).
}

Mais à frente acrescentava o seguinte Burlamaque: 
O magistério, Senhores, não sei por que, tem caído em tal descrédito, o título honroso e venerado de mestre é olhado com tal indiferença, senão desprezo, que os homens bons e ilustrados recusam-se a aceitá-lo com receio da desconsideração, que daí lhes resultaria (PROVÍNCIA do Paraná. Relatório de 1867, p. 30 a 32 apud CASTANHA, 2008.p 23).

Após fazer tais considerações recusava-se a acatar a ideia da criação da escola normal.

Falta aqui o gosto da instrução, faltavam incentivos para os mestres, faltava ainda o recurso pessoal para escolas desta categoria, e a província é pobre no meio de sua imensa riqueza, afirmava Burlamaque (PROVÍNCIA do Paraná. Relatório de 1867, p. 30 a 32 apud CASTANHA, 2008.p 23).

Ao final do período provincial o empreendimento de criação e conservação da Escola Normal não havia sido exitoso. Até essa determinada época, a escola normal criada e revista em seu projeto basilar destinava suas vagas ao sexo masculino. $\mathrm{O}$ ingresso do contingente feminino ao magistério continuava se dando por meio de concursos públicos ou pelo treinamento prático. Com o processo de industrialização ervateira a profissão permanece caracterizada pela dedicação missionária, mas agora também pela feminilização da mão de obra que não exigiria remuneração compatível com a responsabilidade de educar e alfabetizar. Contraditoriamente se exigia da professora provas de habilitação dada a necessidade de melhorar a instrução pública.

Na década de 1920 aproximadamente a escola normal no Paraná começa a passar por uma reorganização que se fundamenta em princípios argumentos higienistas, morais e cívicos. Além do conhecimento elementar e dos necessários métodos, o professor deveria conhecer a organização do Estado, pois a ele caberia a formação do cidadão para o exercício do voto.

A disciplina recomendada para o currículo de formação da escola normal que mostrava a função da educação e, por conseguinte a do professor seria a história: “a de propiciar noções sobre uma nova organização do Estado no qual os cidadãos escolheriam seus governantes” (Miguel, 1997, p.2169). 
O declínio provincial paranaense vai inaugurar no Estado um discurso liberal de preparação das classes empobrecidas para o advento da industrialização em que os desvalidos ocupariam trabalhos explorados diferenciados daquele até aqui realizados na organização de trabalho agrícola e extrativista. A industrialização do mate e a venda de terras produzem o surgimento de povoados e núcleos populacionais que geram aumento de matriculas e obrigatória criação de escolas. Embora a escola normal se configurasse para a formação técnica e para preparação do cidadão paranaense, criaram-se grupos escolares seriados e erigiu-se a figura do diretor segundo o modelo paulista, mas não se qualificou o professor e de acordo com Wachowicz, L., A. (1984, p. 304). Tais medidas foram tomadas no Paraná, somente em 1914, e "com dificuldades para se encontrarem professores para todas as séries”.

Com a reforma do ensino no Paraná de 1920, proposta por Pietro Martinez, a escola normal deveria primar pela eficiência e racionalidade aos moldes da fábrica. Criam-se as escolas normais de Ponta Grossa e Paranaguá. “A primeira serviria a uma grande zona consideravelmente povoada, abrangendo todo o norte do Estado e a segunda receberia a juventude de toda a faixa marítima. A criação desses estabelecimentos viria facilitar extraordinariamente a tarefa de formar professores em número suficiente. (Relatório oficial, 1920, p. 22)”.

Seguindo as trilhas das reformas iniciadas por Martinez, Lysímaco Ferreira da Costa estabelece as reformas da escola normal, separa-o do ginásio e entabula alterações na matriz curricular do curso de formação de professores. Sendo medidas estas distribuídas em um curso geral, com três anos de duração e um curso especial, com dois anos e meio. De acordo com Lysímaco, o curso geral objetivava "preparar a cultura geral do futuro professor” (COSTA, 1987, p.138). O curso especial intencionava a formação metodológica de acordo com pedagogia de Herbart.

Seguindo referencial das escolas paulistas organizou o grupo escolar anexo à escola normal e duas escolas isoladas para as práticas pedagógicas 
dos futuros professores, (Relatório oficial, 1920, p. 22). Em síntese, a reforma proposta por Lysimaco Costa tinha como centralidade: a educação da população como responsabilidade público/privada, ou seja, de um lado governo e municípios e de outros sujeitos sociais cultos e associações; redução da pobreza: leitura e concomitantemente a criação de hábitos morais e mentais desenvolvidos através dos Trabalhos Manuais que combateriam a indolência assegurando o hábito do trabalho produtivo; combateriam o analfabetismo, afirmariam a racionalidade, desenvolveriam os conhecimentos concretos e úteis ao labor e ao progresso brasileiro, como afirma Miguel (2004).

Para Lysimaco Costa importava mais formação moral (católica) dos professores do que sua formação intelectual e, portanto, foram contratados normalistas recém-formados, obedientes ao Estado, em substituição àqueles professores que eram considerados livres pensadores ou eram críticos da Igreja Católica, no dizer de MIGUEL (1992). Assim o tripé da formação que moldaria o caráter da população paranaense seria o mesmo tripé com que se decidiu formar os professores/as normalistas: na concepção higienista, cívica e moral.

Posterior a 1923 a Escola Intermediária alcunha-se como Escola Normal Primária e a Escola Normal que naquele momento passa a se designar como Escola Secundária; destinam-se, ambas, à formação de professores/as para as instituições escolares da capital (OLIVEIRA, 1994, p. 217).

A administração de Vargas e a do interventor Manoel Ribas no período do Estado Novo (1937-1945) mantiveram estreita relação e, neste contexto histórico de instabilidade política, refletida na situação econômica e social do país, potencializava-se a colonização do Norte do Paraná, dandose maior atenção à diversificação na agricultura no interior e intensificandose a produção industrial na capital. Houve expansão também no campo educacional e a proposta pedagógica do então Secretário de Estado Erasmo Pilotto, fundamentada nas diretrizes da Pedagogia da Escola Nova, marcaria 
originalmente a educação primária no Paraná durante o governo de Moisés Lupion. A ação política e pedagógica desse intelectual e administrador público é o núcleo dessa análise reflexiva.

Segundo Tanuri (2000) as ideias escolanovistas orientaram o curso normal não apenas em sua concepção didático pedagógico, introduzindo disciplinas metodológicas de cunho profissionalizante, mas também anteciparam as Escolas Normais Rurais, criadas em Brasília, anexas aos grupos escolares e com duração de apenas dois anos. Seu programa constituía-se de aprofundamento de matérias do ensino primário, somadas às práticas de ensino. É a consagração da dualidade da escola de formação de professores, como afirma TANURI (2000):

[...] por um lado, certa expansão de escolas normais de nível menos elevado, mas compatível com as possibilidades da época e as peculiaridades regionais e, por outro, a consolidação das escolas normais como responsáveis pela preparação do pessoal docente para o ensino primário. (TANURI 2000, p. 71)

A partir da década de 1930 aventou-se a importância do papel do Estado na Educação à necessidade da implantação de uma política nacional de ampliação do ensino, assim como a expansão da escola pública, dada a necessidade de garantir o direito constituído à formação escolar.

Entre a década de 1930 e 1940 surge o movimento ruralista, com uma fachada de alguns ideais socializantes e humanistas, e naquele momento se propunha a discutir ideologizadamente o papel da educação rural inserida no projeto de Estado nacional: esse discurso sobre a educação rural está imbricado ou relacionado às questões de superpopulação urbana, desemprego, e colonização interna. A escola para a cidade, para o meio urbano estaria definida como "natural”, a zona rural, no entanto, aonde as forças civilizatórias ainda não chegaram, necessitava de uma escola produtora de subempregos e de relativas práticas integradoras, capazes de fazer com que homens e mulheres se sentissem adaptados ao meio. E, ao mesmo tempo, a escola deveria preparar para que esse homem aprendesse o 
suficiente para relacionar-se economicamente e se tornar produtivo no meio rural.

TANURI (2000) postula que Movimento Ruralista teve:

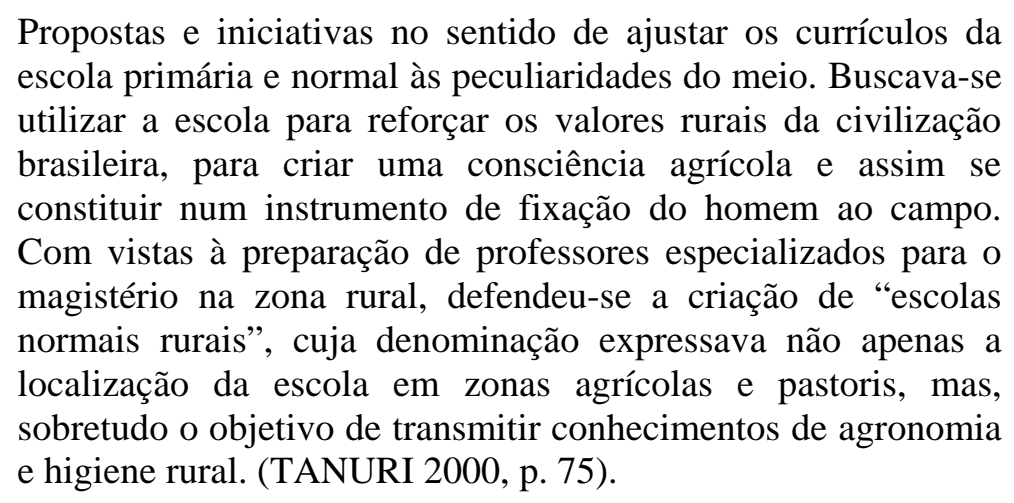

A Lei Orgânica do Ensino Normal - Decreto Lei n. 8.530, de 2-11946, Capítulo III, inciso $4^{\circ}$ normaliza os Tipos de Estabelecimentos de Ensino Normal, constituindo em três: o curso normal regional (destinado o primeiro ciclo de ensino normal tão somente a regência do ensino primário), a escola normal (destinado segundo ciclo desse ensino a formação geral de professores primários com curso ginasial). E o instituto de educação (além dos cursos próprios da escola normal, ministraria o ensino de especialização do magistério e de habilitação para administradores escolares do grau primário). Em seu Artigo $6^{\circ}$ delibera que aos alunos que concluíssem o segundo ciclo de ensino normal seria assegurado o direito de ingresso em cursos da faculdade de filosofia, ressalvadas, em cada caso, as exigências peculiares à matrícula.

No que diz respeito à formação de professores para as escolas rurais no Paraná, as mesmas foram idealizadas a partir do modelo da educação mexicana, visando uma educação adaptadora do homem ao meio rural e integradora do trabalho intelectual/braçal de acordo com a realidade campesina, visando à fixação das famílias a terra. A adaptação das missões culturais mexicanas constituiu-se o germe da Escola Normal Regional no estado: instaladas as escolas, jovens concluintes do curso primário poderiam, conforme dispunha Erasmo Pilloto, dedicar-se-iam ao ensino, tendo esses novos professores, após as devidas orientações, a 
responsabilidade de agentes sociais das comunidades, tendo como meta complementar o aperfeiçoamento cultural e profissional dos professores rurais, integrando homens e mulheres da comunidade ao progresso cultural desejável à nação (Pilotto, 1959, p.57).

No México a educação rural surgiu pós-revolução (1917) em decorrência da necessidade de reforma agrária e melhor utilização de recursos naturais. Segundo Lourenço Filho, a política Educacional seguia dois princípios: “o da ação federal no ensino e o da escola de Ação social”. (LOURENÇO FILHO, 1952 p. 114). Foram então criadas as Missões Culturais que deveriam arrebanhar jovens que no interior do país houvessem concluído o primário e fazer o necessário convencimento para que se dedicassem ao ensino primário. Os jovens missionários deveriam dirigir-se as localidades e lá permanecerem orientando os professores até o estabelecimento de suas escolas objetivando

Neste ínterim a educação rural no Estado do Paraná era de extrema precariedade a as professoras da zona rural mal tinham a formação primária, daí surge à inquietação quanto à necessidade de levar, estender, a experiência das Missões Culturais para o interior do Estado. Esses jovens deveriam permanecer algum tempo em cada localidade para orientar os futuros professores e instalar escolas e os novos professores tinham por missão:

(...) atuar como mentores e líderes sociais desinteressados de pequenas comunidades, e cujos objetivos acessórios [eram]: procurar o melhoramento cultural e profissional dos mestres rurais e integrar a gente adulta da comunidade no progresso cultural médio desejável da nação. (PILOTTO, 1959. p. 57)

Portanto, as Escolas Normais Regionais poderiam ser cursadas ao término do curso primário e preparavam professores para as escolas isoladas. Essa proposição representou uma política de formação de professores que buscou suplantar os índices de carência de professores que sequer conheciam os rudimentos de leitura e da escrita nos rincões do estado. 
MIGUEL (1992) relata que Pilotto adaptou as missões culturais mexicanas experimentalmente para a realidade das escolas rurais das cidades de Palmeiras e Cerro Azul e que vieram a tornar-se o núcleo inspirador para a realidade das escolas rurais paranaenses expandindo-se para os sertões do Norte Pioneiro do Paraná, tornando-se as Escolas Normais Regionais como passaram a ser denominadas no Estado. Trata-se da invenção de uma instituição que nasce de uma política contingencial a ser adotada para o momento histórico e situação caótica da formação dos professores da zona rural do Paraná. A Escola Normal Regional é uma criação de Pilotto e uma pioneira originalidade institucional do Paraná.

Paradoxalmente, ao exorbitante numero de professores concentrados nos centros urbanos maiores do Paraná, havia um déficit impar no interior do estado, visto que as escolas normais concentravam-se nas maiores cidades: Curitiba, Paranaguá, Ponta grossa, Londrina e Jacarezinho.

Estávamos vendo os passos da evolução final do processo de formação de professores no Paraná. A última medida de importância nesse sector foi à disseminação, no interior do Estado, de cursos normais regionais, isto é, escolas de formação de professores dentro do $1^{\circ}$ ciclo do grau médio, exigindo- se, porém, a idade mínima de 13 anos para ingresso. Isso em 1949 e 50. O caso é que, naquela data, mais da metade dos professores primários do Estado tinha apenas o curso primário ou mal tinha o curso primário. [...] E via-se o «déficit» no alarmante fato de todo o ensino da zona rural estar entregue a professoras comumente de formação eficientíssima, nos melhores casos de formação apenas de curso primário. (PILOTTO, 1953, p.97).

A matriz pedagógica dessa ação estatal fundamenta-se na concepção teológico-pedagógica da Didática Magna de João Amós Comênio, a noção de escola democrática unificada, entendendo que a educação deveria ser para todos independente de classe social ou gênero, e assim a escola normal regional para formação de professores primários se constituiu, aceitando alunos do sexo feminino e masculino, e sua ênfase não foi a ciência, mas a instrução e moral. O ensino de dava a partir do que lhes era comum, "passoa passo e com muita ordem" ou segundo Pilotto (1959): 
(...) proceder passo a passo e acabadamente. Trata-se de um quadro de cinco pontos composto por I- ensino inicial da leitura; II- ensino inicial da aritmética; III- aulas ao ar livre; IVrecreação e V- Associações de amigos da escola e associações de ex- alunos (PILOTTO, 1959. p. 32).

Aqui vamos nos deter ao item V: a criação de Associações de Amigos da Escola. Baseada no princípio de necessidade mútua entre comunidade e escola: um precisa do outro, PILOTTO igualmente criou outra inovação institucional no Paraná. Resultou da reclamação dos campesinos de que as escolas isoladas não eram devidamente inspecionadas, e dos professores do afastamento da família e da falta de sua cooperação com as atividades e necessidades cotidianas da escola.

A organização simples e eficiente com objetivos bem definidos da experiência mexicana instruindo criação uma Associação de Amigos junto a cada escola isolada rural serviu uma vez mais como referencial para Pilotto. Uma associação de cada escola:

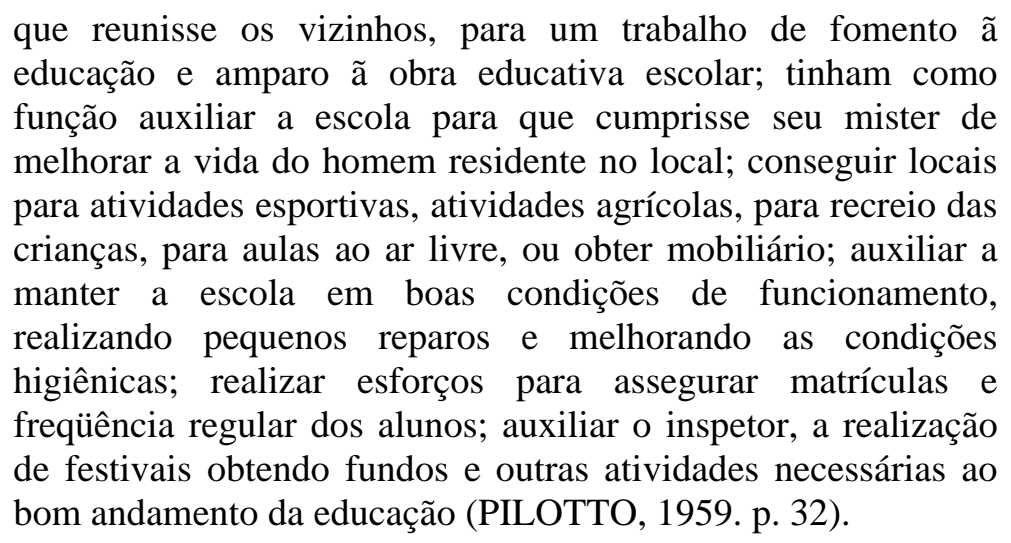

A escola normal regional foi uma genuína criação da política de expansão das escolas de formação de professores do secretário estadual do Paraná Erasmo Pilloto. Seu escopo ideológico é eclético, de matriz escolanovista, assumindo seus ideais e concepções matriciais, com sincretismos de matiz assistencialista e culturalistas, derivados dos princípios que marcaram as missões culturais mexicanas, inspiradoras e modelares.

Daí a política de levar a escola normal para o interior, recrutar, em cada município, os seus alunos aí mesmo, entre moças do 
lugar, e que aí ficassem, depois, exercendo o magistério. Foram, dentro desse espírito, criados 24 cursos normais regionais [...] Qualquer um que fosse, então, ver algumas dessas escolas, veria que ardente espírito de idealismo se estava vivendo ali: Haveria de ver como mestres e alunos estavam identificados num colossal esforço em favor da escola. Como pensavam com grandeza no magistério. Como realizavam com o mais belo entusiasmo [...] (PILOTTO, 1953, p. 98).

O funcionamento desse Curso Normal Regional estava condicionado à existência de um curso primário e de duas escolas primárias isoladas a ele interligadas e que serviriam de prática pedagógica aos alunos deste curso. A formação do professor primário se constituía de uma proposta de profissionalização especializada que o ajudasse a entender as necessidades da profissão, assimilar a cultura geral e apropriar-se da formação da personalidade do educador. Podemos considerar sobre os Cursos Normais Regionais que a concepção de Pilotto era de natureza dualista: a formação dos alunos/as dos Cursos normais regionais previa dois níveis: aqueles que compunham o grupo da média da classe e os que estavam acima dessa média, e isso se considerando os pressupostos de inteligência e personalidade.

Ao outro contingente, se relegaria um "trabalho de caráter mais prático, mais de acordo com o seu desenvolvimento, com as suas possibilidades" (PILOTTO, s.d.p.132); no entanto todos receberiam uma educação geral sólida que lhes garantisse o domínio atrelado à função social daquele contexto.

Começamos por referir um texto modelar, que pode ser importante documento político a fornecer dados esclarecedores sobre a motivação institucional do Estado ao, nos anos da pós-segunda guerra mundial, procurar definir políticas de implantação de polos educacionais pelo estado do Paraná afora:

De outra vez, fui até uma das localidades, no norte do Estado, situada no extremo atingido, naquele momento, pela avalanche da penetração que, oriunda dos outros Estados do Brasil e quase de todos os outros Estados, vem, rasgando e queimando a selva, atrás de uma das prometidas «Canaans» com que a natureza, de tempos em tempos, e em lugares diversos, acena aos homens 
com o lenço da esperança das fortunas vertiginosas e tantas vezes é apenas a fortuna de uns poucos e a ansiedade e a busca inquieta de todos aqueles nómades.

Pude ver, então: o chão ainda se conservava cálido do fogo recente que destruirá a mata para dar lugar à cultura do café. O fogo não se havia ainda apagado de todo. E ali estavam homens morando em casas feitas com a madeira que, cortada na antevéspera, ainda tinha seiva, os troncos toscos das árvores amarrados uns aos outros. Uma família inteira em uma coberta de palha, sem paredes. Barracas de lona. $\mathrm{O}$ fogão ainda ao ar livre na semeadura de verdadeiro acampamento. O café, plantado, precisa quatro ou cinco anos para começar a produzir. E muitos, (falo agora com um preto rude e moço vindo de Minas), não são donos da terra. Nunca o serão. Nem pensam em sê-lo. Já vieram com vontade só de serem empregados.

E mais de duzentas famílias já estão morando aqui, vindas no último ano, mas não moram neste lugar onde agora o favorecido dono da empresa de colonização está levantando a igreja onde nenhum padre vai vir ainda por muito tempo. Onde moram, então ? "Aí pelos matos». Cada sítio está separado dos outros sítios pelo mato, a selva selvagem. Cada homem está separado dos outros homens. Aqui não há nada mais do que a mata para vencer, a terra como um prodígio, e homens nómades talvez pela esperança. Penso na escola que é preciso levantar aqui. Que educação devemos àquela criança que ali está, na minha frente, - a escola talvez tarde ainda a chegar e, quando chegar, que escola vai ser? Em frente de mim, está uma mulher grávida e tem vinte anos. [...] Que escola temos de dar a esses nossos irmãos? (PILOTTO, 1953, p. 78-79).

A força descritiva e argumentativa do Secretário Estadual de Educação Erasmo Emiliano Pilotto (1953) pode revelar a intenção e concepção de educação que se pretendia oferecer naquele momento histórico aos milhares de trabalhadores que migravam em hordas de nômades em busca de trabalho, vida e moradias dignas. Será preciso decifrar as premissas políticas e educacionais dessa trágica descrição e intenção.

Nosso enfoque se baliza com destaque aos aspectos econômicos, políticos e sociais que determinam as ações dos sujeitos históricos, procurando prescindir de uma visão episódica e factual. Nossa ponderação é de que a história deve ser compreendida a partir da análise das condições concretas com as quais os homens se relacionam para produzir a existência, dos interesses divergentes produzidos pela divisão social do trabalho e pelas 
forças contraditórias em que engendram o movimento da história. É ainda Pilotto (1954) que descreve a pobreza e rudimentariedade de nossas professoras paranaenses nessa década, e notadamente parecer manejar uma rigorosa analise econômica de base, destoando da cartilha idealista e moralizante de muitos agentes políticos de sua época.

[...] E assim poderíamos continuar, por centenas de cartas que temos em nosso poder, e as cartas pertencem aos mais vários municípios do Estado, às mais várias regiões económicas, a zonas de culturas, diferentes, habitadas por homens de raças diversas, italianos, russos, caboclos, poloneses, japoneses, ucranianos... localizados em zonas de café, de mate, de trigo, ou de mineração, de serrarias. . As professoras não se conhecem umas às outras e todas falam num só tom e quase numa só frase. É a monotonia de um testemunho para compor o quadro mais vivo da nossa escola isolada rural. A implacável presença do fator económico, «... mas também quando faltam, não posso dar instrução». (PILOTTO, 1954, p. 77-78)

Seguindo este modelo, os professores, alunos do Curso, eram instados a promover a elevação cultural do homem do campo. Elaborou também instruções que tinham por finalidade formar o professor para ser um profundo conhecedor do meio no qual a escola estava situada, com consciência dos problemas regionais e liderar a comunidade para a solução dos mesmos. Quanto à ação escolar propriamente dita, os alunos deveriam estudar os problemas pedagógicos relacionados à região e promover a cultura pedagógica orientando não só os pais dos alunos, mas toda a comunidade.

No currículo proposto para o Curso Normal Regional, previsto na Lei Orgânica do Ensino Normal, Instituída pelo Decreto-Lei 8.350, de 02 de janeiro de 1946, as concepções de educação, arte e cultura se interrelacionam num ideário explicitamente escolanovista, demonstrando como havia a intencionalidade da preparação cultural e a elevação do nível do saber do povo, por meio da difusão do conhecimento e da cultura.

[...] Considere-se, ainda, a importância desse fato, não apenas do ponto de vista da formação para o magistério, mas da oportunidade de ampliação da cultura geral no interior do Estado (PILOTTO, 1953, p. 98). 
[...] Considere-se, ainda, que os cursos ginasiais do Estado [...] que abrigam 4 vezes mais que os cursos de formação de professores, custaram 24,08 \% das despesas estaduais com a educação, isto é, quase dez vezes mais do que aqueles cursos. (PILOTTO, 1953, p. 98).

Isso se evidencia na matriz do Normal de Nível Ginasial para formação de professores primários, as únicas disciplinas estabelecidas para as três séries que faziam parte da estrutura curricular do Curso eram de arte e cultura geral. Podemos observar o escopo escolanovista de PILOTTO no Ante Projeto de Lei Orgânica da Educação do Estado (1949), constante dos objetivos gerais inspirados e princípios de solidariedade humana e da liberdade, que assegurasse o pleno desenvolvimento das potencialidades do educando contribuindo para sua integração na sociedade brasileira regional e local.

Ainda seu enfoque dado ao desenvolvimento cultural do Estado, sobretudo às massas excluídas da população via educação, mais precisamente, através da analise que faz sobre as reformas anteriormente efetivadas por Martinez e Lysímaco Costa quanto a oferta de cursos de formação de professores primários:

É verdade que o Diretor da Educação, pessoalmente, apoiava a vida das Escolas Normais. Mas os órgãos técnicos da Diretoria eram eminentemente conservadores, com um ou outro elemento, apenas, partidário da renovação educacional que se agitava por toda a parte, no mundo. E, assim, aqueles elementos de exceção, uma vez ou outra, conseguiam estimular medidas e impulsos renovadores. A linha geral, porém, era conservadora. Em 1948, assumimos a direção da, já então, Secretaria de Educação e Cultura. Levamos, para lá, o espírito das Escolas Normais. E procuramos pôr em ação, nos pontos vitais, a elite dos professores que as Escolas Normais vinham formando, dentro do novo espírito (PILOTTO, 1953, p. 84).

PILOTTO preocupava-se com a expansão da rede de ensino público em seu aspecto quantitativo e intencionava organizar o sistema educacional e cultural e moderno sob responsabilidade do Estado, articulando suas diferentes instâncias de modo a garantir qualidade mínima de ensino escolar. O primeiro ciclo do grau médio ou Normal Regional deveria ampliar a cultura geral do aluno e orientá-lo para o trabalho. O intento do 
segundo ciclo do grau médio deveria proporcionar ao aluno a cultura e o desenvolvimento de talentos intelectuais. As metas de grau superior eram reservadas aqueles que tivessem potencialidade intelectual superior e objetivava orientar os alunos conforme segue:

As escolas do primeiro ciclo do grau médio deveriam ampliar a cultura geral do aluno, sondando-lhe a vocação e orientandolhes para o trabalho (Art. 15, I, a). [...] As do segundo ciclo do grau médio destinavam-se a proporcionar aos alunos "a cultura e a utilização de suas aptidões especiais" (Art. 15, I, b)

As de grau superior destinar-se-iam aqueles que tivessem "aptidões intelectuais superiores" e tinham o objetivo de orientar os alunos "para especializações cada vez mais definidas, de fomentar a pesquisa e divulgar a cultura" (Art. 15, I, b) BRASIL, 1937)

Essa visão dualista traduz o pensamento liberal escolanovista da época, porém, não se pode negar as relevantes contribuições históricas desta concepção para os Cursos de Formação Docente do Paraná, visto que trazia em seu bojo o germe da superação de formas conservadoras e autoritárias e tradicionalmente excludentes de formação docente:

O objetivo da formação do mestre é promover a liberação de todas as suas forças espirituais que serão, depois, postas em serviço nos trabalhos da educação.

Não é a prática, irmã gémea da rotina, que se faz necessária, mas as atividades que promovam a liberdade espiritual criadora do futuro mestre. E, visivelmente, essa liberdade espiritual criadora só se pode gerar no contato com os Princípios, com as Ideias Gerais, que se apresentam bem naquelas atividades da Filosofia, da História, etc. Demais, as atividades na Música, etc, corretamente orientadas, são fontes de expansão da personalidade, criação pessoal, liberdade espiritual, criação permanente [...] A maior parte dos que afluem à Escola, sem que se deva rejeitá-los, sem que se possa fazê-lo, não têm nem desenvolvimento nem base de cultura para um trabalho em tal feitio [...] (PILOTTO, 1953, p. 95).

Fica claro que enquanto a reforma de Lysímaco Ferreira embora liberal direcionava-se a formação de hábitos de disciplina para o futuro cidadão trabalhador, Pilotto claramente e sua intencionalidade era a formação erudita dos professores extensiva à população via escolarização. Nisto inclusive desviava do ideário de cientificidade de preparação do 
trabalho técnico para o trabalho na indústria, objetivo do projeto escolanovista comprometido com a política de desenvolvimentista da nação direcionando a educação paranaense para os campos sociologicamente espirituais humanistas: arte e culturais.

Consideramos relevante retratarmos Erasmo Emiliano Pilotto, dada a profícua intelectualidade e vasta obra de tão notável intelectual paranaense. Por sua importância no contexto de nosso estudo, e por emanar dele a criação do Normal Regional no Paraná como intervenção possível para formação de professores, especificamente para as camadas da população empobrecidas, oriundas das áreas isoladas e, em específico, ao que tange ao Norte Pioneiro do Estado.

Erasmo Emiliano Pilotto nasceu em 1910 e foi ativista engajado do Movimento pela Escola Nova. Intelectual de formação tecida nos embates da década de trinta, entre quarenta e cinquenta, sobressaiu-se na esfera da política educacional, congruente com as altercações nacionais e internacionais que permearam ao longo do período, a organização dos sistemas públicos de ensino, os processos de formação de professores, as práticas escolares, a definição dos fins e dos objetivos da educação nacional.

O pensador, escritor, professor, político e crítico de arte têm uma ampla produção caracterizada pela interlocução e pelas mediações em diversos campos da cultura, da Pedagogia, das Artes e Literatura. Pilotto distinguiu-se por suas produções e disposição intelectual e política de intervir sobre o campo da cultura paranaense, sobretudo nos processos organizativos da escola pública e sobre os processos de formação de professores paranaenses.

Envolvido com projetos educativos desde 1927, quando optou pela carreira de professor ao ingressar, como aluno, na Escola Normal de Curitiba, participou ativamente da criação de instituições como o Centro de Cultura Filosófica, o Centro de Cultura Pedagógica, a Universidade Popular, e do boletim intitulado $O$ ideário da Escola Nova, círculos dedicados à divulgação dos ideais escolanovistas, além da Escola de Música e Belas Artes do Paraná, aonde chegou a atuar como professor. (PILLOTO, 2006, p 34) 
Erasmo Pilotto, intelectual paranaense da educação sempre esteve próximo do Movimento pela Escola Nova E manteve-se em contato com o ideário da escola ativa que colocava o do aluno no centro das preocupações educativas postulando a construção do conhecimento por meio da experiência. Representante do escolanovismo no Paraná e das renovações que a Escola Nova a partir da década de 1930 do século XX mobilizou intelectuais em torno de um projeto que visava profundas reformas no contexto educacional nacional e professava suas ideias que foram proeminentes.

Defendia o processo educacional integrado à vida e à cultura sobre tudo a partir do referencial de Dewey. O aporte teórico por meio do qual direcionava suas reflexões criticando o tradicionalismo em defesa a princípios tais como o caráter público e laico da educação. Esteve na vanguarda de diversas ações no contexto cultural paranaense que marcaram sua época e produção intelectual.

De acordo com Vieira (2001) intelectuais associados a Pilloto, a arte a cultura defendiam iniciativas em nível nacional no sentido de definir políticas públicas para a educação, a organização de um sistema de ensino, a reformulação dos processos pedagógicos na formação de professores e a reformulação metodológica de ensino.

Pilotto participou diretamente dos embates epistemológicos e das políticas do campo educacional do Estado e da nação nas décadas de quarenta, cinquenta e sessenta Vieira (2001). Sendo inclusive algumas das iniciativas se suas iniciativas como homem público, político e intelectual no âmbito da organização do sistema escolar paranaense a fundação do Instituto Pestalozzi, para alunos de pré-primário; a instauração de processos pedagógicos domo estivais de arte nas escolas públicas como Secretário de Estado da Educação, de 1942 a 1949 e a criação dos Cursos Normais Regionais no interior do Estado.

No Instituto Pestalozzi, instituição particular, com caráter experimental que funcionou como laboratório das ideias da Educação Nova, Pilotto articulou a vivência pedagógica 
considerando o desenvolvimento do educando. Tal desenvolvimento era estimulado por atividades que colocavam o aluno em contato com as melhores obras da cultura humana na música, nas artes plásticas (MIGUEL, 1992).

Assim o componente curricular do Curso Normal Regional no interior do Estado não poderia ser de outra forma era de ideário liberal escolanovista enfatizando-se neste caso em particular a grande ênfase dada à cultura geral e a arte enquanto função formativa: Desenho e Trabalho Manual como disciplina e distribuídas nas quatro séries. Currículo também é acrescido de Ciências Naturais, Anatomia e Higiene. Mais tarde acrescido quando são implantadas as disciplinas de Inglês, Frances e Organização Social e Política Brasileira:

Já nos cursos normais regionais, previstos na Lei Orgânica do Ensino Normal, instituída pelo Decreto-Lei 8.350, de 2 de janeiro de 1946, as únicas disciplinas que compunham o currículo das quatro séries do curso eram Português, Educação Física, Desenho e Caligrafia e Canto Orfeônico; todas as outras eram ministradas em uma, duas ou três séries apenas. Da mesma forma e mediante a mesma lei, que "através dos Cursos Normais de $2^{\circ}$ Ciclo objetivava formar professores primários, [...] as únicas disciplinas presentes nas três séries que compunham o curso" eram Música e Canto Orfeônico, Desenho e Artes Aplicadas, Educação Física, Recreação e Jogos. (FERRAZ \& FUSARI, 1993, p. 15).

Quanto à música, Villa-Lobos desencadeara já na década de 1930 um grande movimento que, nos anos 40 e 50 tomaria vulto nacional, e que envolvia não apenas a prática de canto orfeônico, isto é, de canto coral, pelas crianças da rede regular de ensino em todo o Brasil, mas também a formação de professoras, especialmente vinculadas à Escola Normal, no âmbito nacional. Em nível estadual Pilotto corroborava:

E, visivelmente, essa liberdade espiritual criadora só se pode gerar no contato com os Princípios, com as Ideias Gerais, que se apresentam bem naquelas atividades da Filosofia, da História, etc. Demais, as atividades na Música, etc, corretamente orientadas, são fontes de expansão da personalidade, criação pessoal, liberdade espiritual, criação permanente (PILOTTO, 1953, p. 95). 
Objetivou-se imprimir a nacionalidade na esfera da educação valorizando a cidadania, o patriotismo e o nacionalismo cooptando a juventude do Estado Nacional, assim como a educação física era reforçada para a criação de hábitos e práticas de higiene nas crianças e jovens. (PR. Decreto $\mathrm{n}^{\circ}$ 2.072, de 8 de março de 1940). Assim, segundo Lenharo (1986) a "getulização da cultura escolar" e través dos textos escolares não obstante teve o professorado como público alvo privilegiando de uma mensagem embasada em discurso de afetividade e solidariedade, exaltando a personalidade do Chefe da nação, e os atributos históricos da época, nacionalidade, cultura nacional e porvir glorioso. E cabia ao professor e à escola envolver os alunos, em um "apostolado cívico", restaurador da harmonia originária da sociedade brasileira:

A palavra do professor não transmite apenas conhecimentos e noções do mundo exterior. Atua igualmente pelas sugestões emotivas, inspiradas nos mais elevados sentimentos do coração humano. Desperta nas almas jovens o impulso heróico e a chama do entusiasmo criadores. Concluo, por isso, a utilizá-la no puro e exemplar sentido do apostolado cívico, infundindo o amor à terra, o respeito às tradições e a crença inabalável nos destinos do Brasil (Mensagem de Getúlio Vargas. Revista de Educação, 1943 apud MONARCHA, 1999, p.60 -61).

Visualiza-se então no rol das ações dirigidas o reforço da ideologia da educação nacionalista da era Vargas desencadeadas e coordenadas na Educação pelo próprio presidente e pelo Ministro Gustavo Capanema na inclusão de disciplina escolar. De acordo com Monarcha (1999), “o movimento de canto orfeônico idealizado e conduzido por Villa lobos, tinha como finalidade nas escolas colaborar com os educadores na obtenção da disciplina voluntária dos alunos”. (Monarcha, 1999, p.60 -61).

Engendrava-se, portanto, no país e no estado um projeto de expressão artística musical, como forma de cultura político educacional que autoafirmava a cultura nacional através da prática persuasiva do canto coral e da formação de corais, ou ainda nas entoações regionais com o intuito de animar as festas escolares infantis desenvolvendo a afetividade, o cultivo de ideais cívicos numa perspectiva de política educativa. 
Apesar da grande compreensão discursiva do Governo e seus pares, que em seu “entusiasmo pela educação” preconizavam compreendê-la como base da organização nacional e da ingenuidade política do "otimismo pedagógico" dos educadores acreditando que poderiam transformar a sociedade pela ação da escola, com as análises coligidas, com o desenvolvimento da pesquisa pudemos ampliar e melhor compreender e interpretar o cenário educacional da sociedade neste momento histórico.

Neste período, ante a necessidade de mão de obra especializada, direciona-se a educação para a formação grassando a qualificação de recursos humanos voltadas ao desenvolvimento econômico do país. E emparelhada a esta ênfase nominada nacionalista postergou-se o currículo de formação docente a ideias pedagógicas escolanovistas que se manifestam com propostas metodológicas próprias desta concepção pedagógica. Seu substrato ideológico ainda é a teoria do capital social.

Ou seja, as Escolas Normais embora fossem de alçada dos Estados seu fundamento pedagógico continuava mal definido: “[...] não é uma escola secundária, nem tão pouca uma escola profissional, mas sim uma escola de ensino geral, não obstante conduz o ensino do magistério.” (WEREBE, 1997, P. 42.). Assim, a História das escolas Normais no Brasil e no Paraná esteve assinalada por asseverações e alterações político-pedagógicas diversas. Mas, apesar das conjunturas, muitas vezes adversas, essa atuação e demanda atravessou a República chegando a década de 1940/1950, como instituição escolar pública imprescindível em sua atribuição sócio educacional de formadora da categoria de profissionais da educação primária no país.

\section{Considerações Finais}

Nosso intento despretensioso foi buscar compreender como Erasmo Pilloto, intelectual paranaense pouco conhecido, consagrou-se também como grande representante histórico das políticas derivada dos marcos políticos e pedagógicos do escolanovismo. Buscamos evidenciar sua 
concepção de educação, levantar dados que abrem um leque de possibilidades para a compreensão da coerência pedagógica das políticas públicas defendidas por Pilloto, especificamente no concernente à Escola Normal Regional na qual depunha a intenção de desenvolver um princípio realista e uma estratégia política para a realização de um projeto de interiorização emergencial para a formação de professores para a escola primária.

Ao não esperar comodamente por condições propícias para expandir os cursos de formação de mestres, mas ousar criar a partir do referencial das missões mexicanas, num modelo singular e eficiente de curso experimental de formação de mestres, demonstrou talento intelectual e flexibilidade para adequar princípios teóricos a uma realidade inóspita e desafiadora para a educação formal.

Através da ação institucional à frente da secretaria de Estado da educação e, mais ainda, pelos documentos escritos que embasaram suas intervenções, é perceptível que Pilloto entendia a educação como um processo de vivência, experimentação e de construção de conhecimentos, numa relação de liderança e dinamismo do professor e de estabelecimento de parcerias vivas com a comunidade. É nesse contexto que constituiu a Associação Amigos da Escola como original proposta de interação.

O Professor Erasmo Pilotto já defendia a concepção de articulação entre a escola e a comunidade, hoje assumida como novidade nos programas de voluntarismo educacional, ou mais conhecida como Amigos da Escola (1997). Todavia, para ser fiel à história da educação e aos dados originais coletados nesse estudo, parece ser verdadeiro dizer que a concepção de voluntariado educacional, através da proposição das “Associações de Amigos da Escola” tenha sido originária do Paraná, através de seu pioneiro secretário, e não de inspiração recentes.

Participou da criação da Faculdade de Bela Artes do Paraná, à frente da Secretaria do Estado da Educação e Cultura, criou o Conselho Estadual de Arte e Cultura que teria, segundo o então secretário, a responsabilidade 
de estabelecer um elo de comunicação entre a Secretaria e a sociedade civil organizada.

Sua gestão frente à Educação pública paranaense aproximou Educação e Cultura ao ponto de que os intelectuais e eruditos locais e nacionais transitavam tranquilamente entre as duas esferas contemplando sua visão de preparação profissional e para a administração da sociedade sem desvinculála da responsabilidade de manejar o legado cultural como responsabilidade do Estado.

Pilotto foi um intelectual intimamente ligado às questões educacionais no cenário paranaense e brasileiro. A sua trajetória como professor, escritor, político e crítico é vastíssima e caracterizada por uma ampla interlocução e intervenção em diversos campos da cultura: da pedagogia às artes plásticas, da filosofia à literatura. Pilotto se notabilizou pelos estudos e pelas intervenções que realizou sobre o processo de organização da escola pública e, em especial, sobre os processos de formação de professores. Ele participou diretamente das disputas teóricas e políticas do campo educacional paranaense e brasileiro no período que se estende da década de trinta à década de oitenta do século vinte. Investigar o pensamento desse intelectual contribui, a meu ver, para a compreensão da multiplicidade de ideias e de referências teóricas que compuseram o Movimento pela Escola Nova no Brasil. (PILLOTO, 2001. p.3)

Era um intelectual capaz de pensar em função da realidade do seu tempo sem impedir a tensão e o diálogo entre a utopia e a realidade fazendo da experiência sua prova definitiva com inequívoca criatividade e ousadia.

Esses dados ficam registrados como legado de sua atuação ímpar como homem público e testemunhado pelos depoimentos decorrentes de estudos sobre sua atuação, ainda incipientes. Mas, sobretudo, é forçoso dizer que, nas pesquisas desenvolvidas que nos permitem uma análise mais acurada, os vetores apontam para um homem inconformado com a ordem das coisas:

(...) como foi possível chegarmos a 1948, um passo se quer para ultrapassarmos essa situação? [...] Não é humano que nada se tenha feito anteriormente para remediar esse estado de coisas. (PILLOTO, 1952, 8). 
Atribuímos a Pilloto a atitude política de determinar a expansão da educação das crianças das escolas rurais, de áreas isoladas e a disposição ideológica e institucional de garantir a formação pedagógica das professoras do Sertão do Norte Pioneiro do Paraná.

Por último, a oportunidade dessa reflexão nos possibilita ainda repensar uma questão a ser amplamente debatida; a proposta renovadora pillotiana de reforma social pela educação, que através do Movimento da Escola Nova, atingiu os rincões do Paraná. Ele universalizou o ideário escolanovista no Estado difundindo-a para além dos centros urbanos. Sua ação primordial está na base das construções institucionais e materiais que viriam a possibilitar a uma professora da rede estadual hoje escrever essas disposições históricas como pesquisadora!

\section{Referências Bibliográficas}

CASTANHA, André Paulo. Escolas Normais no Século XIX: um estudo comparativo. Revista HISTEDBR On-line, Campinas, n.32, p.17-36, dez.2008 - ISSN: 16762584. Disponível em www.histedbr.fae.unicamp.br. Acesso em 04/07/2011.

COSTA, M. J. F. F. Lysimaco Ferreira da Costa: A dimensão de um homem. Curitiba: Imprensa da Universidade Federal do Paraná, 1987.

LOURENÇO FILHO, M. B. 1952. A educação rural no México. in Revista Brasileira de Estudos Pedagógicos. V.18, n. 45. p. 108-198

FERRAZ, Maria Heloísa C. de T.; FUSARI, Maria F. de Rezende e. Metodologia do ensino de arte. São Paulo: Cortez, 1993a. . A arte na educaşão escolar. São Paulo: Cortez, 1993b.

MIGUEL, Maria Elisabeth Blanck. A Pedagogia da Escola Nova na formação do professor primário paranaense: início, consolidação e expansão do movimento. São Paulo: PUC, Tese de Doutorado, 1992.

. A Escola Nova e o intelectual educador. Araucárias. Palmas, FACIPAL, 2002. p. 07-21, no 01.

MONARCHA, Carlos. Notas Sobre a Educação nacional na "Era Getuliana". História da Educação. ASPHE/FaE/UFPel, Pelotas (6): 57 -58, out. 1999. 
OLIVEIRA, Maria Cecília Marins de. O ensino primário na provincia do Paraná1853-1889. Curitiba: Biblioteca Pública do Paraná-Secret. de Estado da Cultura e do Esporte.

PARANÁ. Secretaria de Educação e Cultura. Boletim, Curitiba, Ano I, no 4, nov./dez. 1951.

PILOTTO, Erasmo. A Educação é direito de todos. Curitiba [s.ed]: 1952.

- Situações do Desenvolvimento Brasileiro e a Educação. Curitiba:

Associação dos Estudos Pedagógicos, 1959.

Direito à educação. Curitiba: Associação de Estudos Pedagógicos,

1960.

TANURI, L. M. Contribuição para o estudo da Escola Normal no Brasil. Pesquisa e planejamento. São Paulo, v.13, dez.1970, p. 7-98.

WACHOWICZ, R. C. Universidade do Mate. Curitiba: APUFPR, 1983.

WACHOWICZ, Lilian Anna. Relação professor $x$ estado no Paraná Tradicional. Curitiba: Cortez Editora, 1984.

VIEIRA, C. E. . Intelectuais e o discurso da modernidade na I Conferência Nacional de Educação (Curitiba-1927). In: BENCOSTTA, M. L. (Org.). Culturas escolares, saberes e práticas educativas: itinerários históricos. $1^{\mathrm{a}}$ ed. São Paulo: Cortez, 2007, v. 1, p. $379-400$.

- O Movimento pela Escola Nova no Paraná: trajetória e ideias educativas de Erasmo Pilotto. Educar em Revista. Curitiba, PR: Ed. da UFPR, n. 18, 2001.

Educaşão e Modernidade no Projeto Formativo de Erasmo Pilotto.

UFPR. Eixo Temático 6: Intelectuais, pensamento social e educação. Disponível em www.sbhe.org.br. Acesso em 11/11/2011. 